\title{
Rancang Bangun Aplikasi Monitoring Performance WiFi.Id PT.Telekomunikasi Berbasis Web
}

\author{
Ayu Maulisa Lindra, Suroso, Jon Endri \\ Fakultas Teknik Elektro, Teknik Telekomunikasi, Politeknik Negeri Sriwijaya, Palembang, Indonesia \\ Jl.Srijaya Negara, Bukit Lama, Kec. Ilir Barat I, Kota Palembang 30139 \\ ayumaulisa.lindra@gmail.com, osorus11@gmail.com, jonendri@polsri.ac.id
}

\begin{abstract}
Internet is the nessecity that widely used today. One of the way to access the internet it self, we can use the facilities provides by PT.Telekomunikasi that is WiFi.Id. in this application, namely "The WiFi.Id Performance Monitoring Application" can be used to improving the WiFi.Id performance for making it always in good condition and stable. This application is made in web base application where is can be useful for checking WiFi.Id performance that distributed in several point in the fields, the preference from this application we can check in one point from several acceess point without needed to check every point with the provision we still getting a signal that emitted by WiFi.Id access point it self. From this application we can check the quality of bandwidth in every access point, we will know speeds of upload and download that giving and also know the value of ping and jitter in every access point that emitte the signal. This application also can show some of active access point in that location.
\end{abstract}

Keywords: Telecomunication, WiFi.Id, Access Point, Bandwidth, Web

\begin{abstract}
Abstrak
Internet merupakan kebutuhan yang banyak digunakan saat ini oleh semua kalangan masyarakat. Untuk dapat mengakses internet sendiri, salah satunya menggunakan fasilitas yang disediakan oleh PT.Telekomunikasi yaitu WiFi.Id. Pada pembuatan aplikasi ini yaitu Aplikasi monitoring performance WiFi.Id berguna untuk memantau keadaan performansi WiFi.Id agar selalu dalam keadaan stabil dan baik. Aplikasi ini dibuat dalam bentuk aplikasi berbasis web yang dapat digunakan saat melakukan pengecekan performansi WiFi.Id yang tersebar dibeberapa titik dilapangan, keutamanaan dari aplikasi ini adalah kita dapat melakukan pengecekan disatu titik dari beberapa access point tanpa harus melakukan pengecekan disetiap titiknya dengan syarat kita masih mendapatkan pancaran sinyal yang dipancarkan oleh access point WiFi.Id tersebut. Pada aplikasi ini kita dapat mengecek kualitas bandwidth disetiap access point tersebut, kita akan mengetahuai berapa kecepatan upload dan download yang diberikan serta mengetahui nilai ping dan jitter disetiap access point yang memancarkan sinyalnya. Aplikasi ini juga akan menampilkan beberapa access point yang sedang aktif dilokasi tersebut.
\end{abstract}

Kata Kunci: Telekomunikasi, WiFi.Id, Access Point, Bandwidth, Web

\section{PENDAHULUAN}

Perkembangan dunia teknologi telekomunikasi dan informasi saat ini berkembang dengan sangat pesat. Salah satu penyebab utamanya adalah perkembangan teknologi internet yang banyak digunakan oleh penduduk dunia termasuk masyarakat Indonesia[1]. Kemajuan yang terjadi saat ini memungkinkan kita mengakses internet dengan menggunakan berbagai pilihan yang ada. Contohnya adalah perangkat keras untuk mengakses internet yaitu melalui jaringan WiFi.Id. Berbagai teknologi baru seperti laser, serat optik, telepon, internet, dan perangkat telekomunikasi lainnya telah memasuki jaringan media 
komunikasi tertulis dan lisan dan hal itu tidak dapat dihindari[2]. Teknologi Komunikasi adalah peralatan perangkat keras (hardware) dalam sebuah struktur organisasi yang mengandung nilai-nilai sosial yang memungkinkan setiap individu mengumpulkan, memproses dan saling tukar menukar informasi dengan individuindividu lain[3].

Wi-Fi merupakan singkatan dari Wireless Fidelity yaitu sebuah media penghantar komunikasi data tanpa kabel yang bisa digunakan untuk komunikasi atau mentransfer program dan data dengan kemampuan yang sangat cepat. WiFi juga dapat diartikan teknologi yang memanfaatkan peralatan elektronik untuk bertukar data dengan menggunakan gelombang radio (nirkabel) melalui sebuah jaringan komputer termasuk koneksi[4]. WiFi.Id merupakan salah satu teknologi layanan yang dikeluarkan oleh PT.Telekomunikasi. Setiap WiFi.Id memiliki access point sebagai pemancar jaringan internetnya. Setiap access point memiliki layanan internet yang harus diperhatikan seperti bandwidth, status UP dan Down dari access point dan lainnya. Oleh karena itu untuk memastikan bahwa layanan yang diberikan oleh perusahaan PT.Telekomunikasi selalu dalam keadaan stabil, maka harus selalu dilakukan pemantauan

Untuk membantu melakukan pemantauan maka dibuat sebuah aplikasi yang dapat melihat gangguan dibeberapa access point yang masih berada dalam jangkauan dengan memasukkan input berupa user dari access point tersebut agar mendapatkan output yang diharapkan. Karena aplikasi ini merupakan aplikasi yang dibuat oleh penulis, maka penulis memberi nama pada aplikasi tersebut yaitu Aplikasi Lindra. Aplikasi ini dibuka melalui laptop atau komputer untuk memudahkan proses pemantauan. Karena aplikasi ini sendiri dibuat berbasis web.

\section{METODOLOGI PENELITIAN}

Penelitian ini merupakan suatu perancangan aplikasi yang menggunakan metode Waterfall dalam mengembangkan Aplikasi Monitoring Layanan WiFi.ID. Metode Waterfall merupakan suatu proses pengembangan perangkat lunak berurutan, di mana kemajuan dipandang sebagai terus mengalir ke bawah (seperti air terjun) melewati fase-fase perencanaan, pemodelan, implementasi (konstruksi), dan pengujian[5]. Perancangan aplikasi ini menggunakan XAMPP dan Visual Studio sebagai pemrogramnya dengan menggunkan beberapa bahasa pemrograman seperti MySql,HTML,PHP,JavaScript dan CSS. 


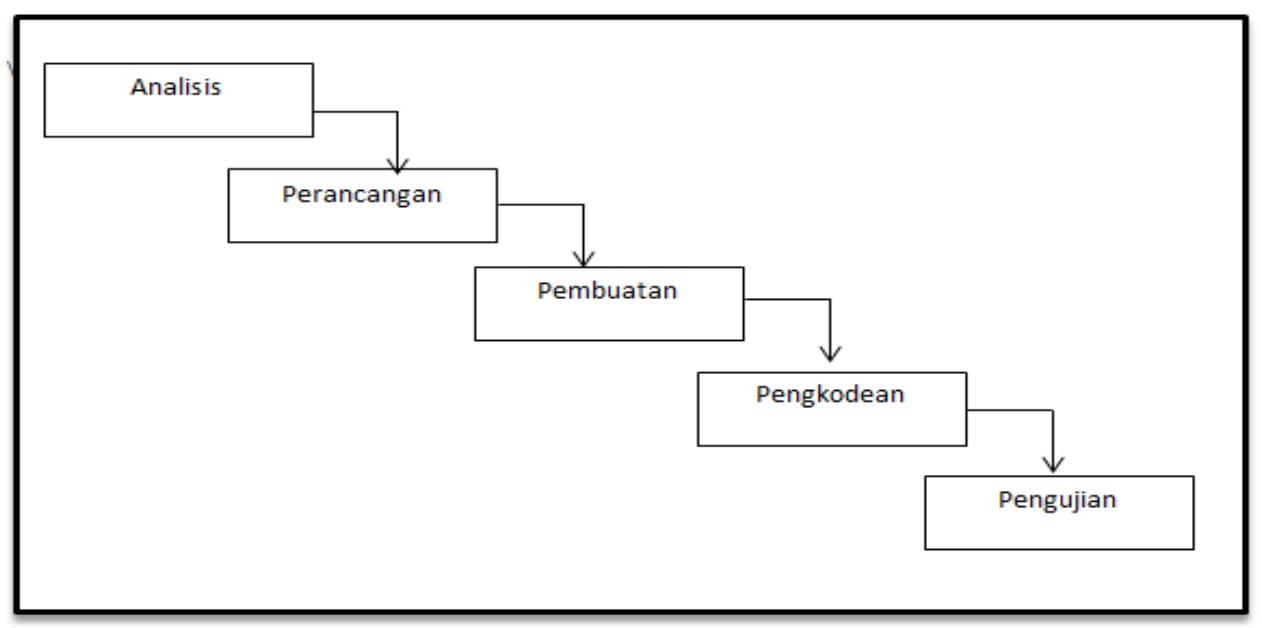

Gambar 1. Kerangka Kerja Pengembangan Sistem Waterfall

1. Analisa : Pada tahap ini penulis, merumuskan apa saja yang dibutuhkan pada perkembangan teknologi saat ini untuk mendapatkan solusi dari permasalahan yang ada.

2. Perancangan dan Pembuatan : Pada tahap ini penulis mulai membuat aplikasi berdasarkan desain aplikasi yang telah dibuat, dan juga memasukan data yang akan digunakan pada aplikasi ini.

3. Pengkodean : Pada tahap ini penulis mulai memasukan kode program, agar aplikasi yang dibuat dapat bekerja sesuai dengan perintah yang diinginkan. Pada tahap ini terjadi proses yang cukup panjang untuk memastikan bahwa aplikasi yang dibuat tidak error dan dapat digunakan dengan baik.

4. Pengujian : Pada tahap ini penulis mencoba aplikasi yang telah dibuat dengan mengambil data dari PT.Telekomunikasi untuk memastikan bahwa aplikasi yang dibuat ini sudah berjalan dengan baik dan benar.

\subsection{Perancangan Perangkat}

Perancangan dan pembuatan aplikasi ini dibagi menjadi dua bagian, antara lain perancangan desain (.xml) program (.java). Perancangan aplikasi ini diawali dengan perancangan diagram blok sistem secara keseluruhan. Blok diagram adalah bagian terpenting dalam perancangan suatu aplikasi, karena dari blok diagram inilah dapat dilihat cara kerja aplikasi secara keseluruhan. Dengan begitu keseluruhan blok diagram aplikasi tersebut dapat menghasilkan suatu sistem yang dapat digunakan atau fungsikan. 


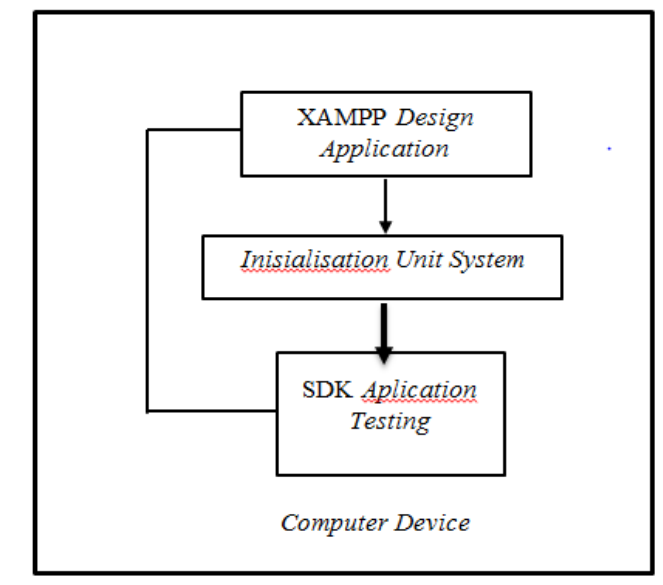

Gambar 2. Diagram Perancangan Perangkat Lunak

\subsection{Perancangan Aplikasi}

Perancangan dan pembuatan desain dari aplikasi monitoring layanan WiFi.Id berbasis web ini menggunakan diagram. Diagram yang digunakan pada tahap ini adalah flowchart activity diagram. Flowchart activity diagram adalah pemodelan perangkat lunak yang menunjukkan alur kontrol atau aliran objek dengan penekanan pada urutan dan kondisi aliran.

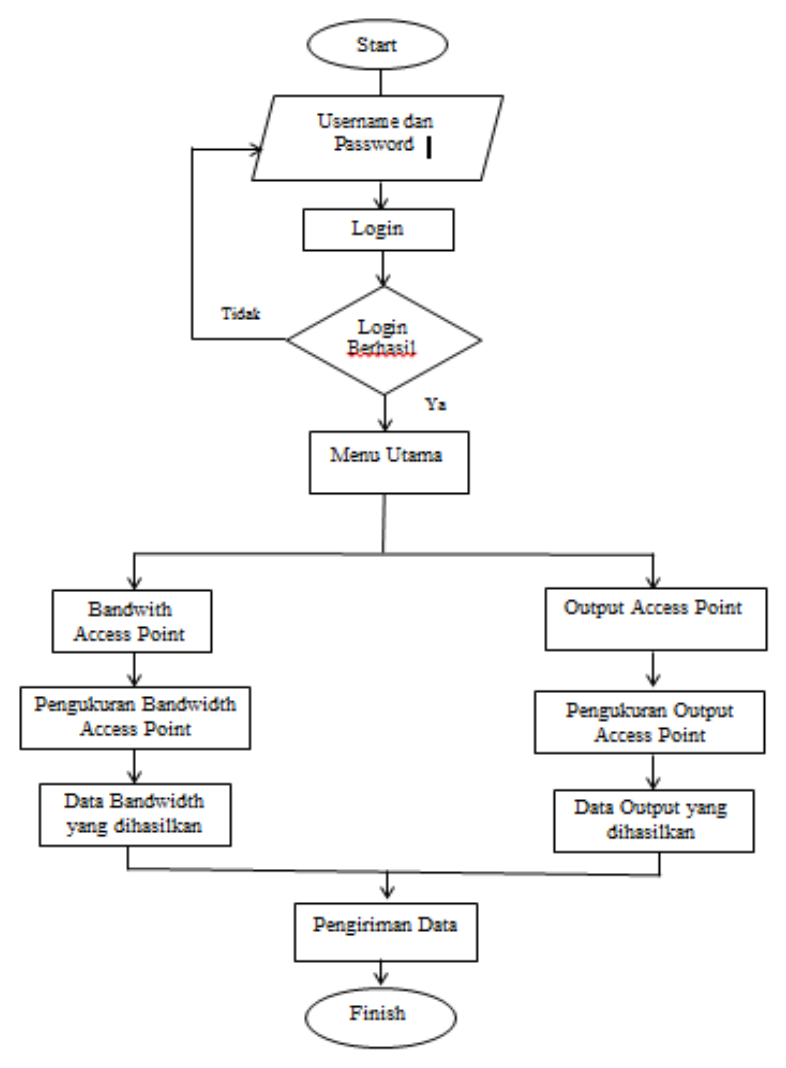

Gambar 3. Flowchart Activity Aplikasi 


\section{HASIL DAN PEMBAHASAN}

\subsection{Hasil Perancangan Aplikasi}

Pada perancangan aplikasi yang dibuat kali ini menghasilkan sebuah aplikasi berbasis web yang befungsi untuk memonitoring performance WiFi.Id yang dapat diakses secara online. Aplikasi ini dapat memonitoring kualitas bandwidth yang ada disetiap access point yang akan dimonitoring. Aplikasi ini mengeluarkan nilai bandwidth berupa Kecepatan Download, Kecepatan Upload, Ping, dan Jitter pada masing-masing access point yang telah disebar dibeberapa titik dilapangan. Aplikasi ini sendiri dapat melakukan proses monitoring dilapangan tanpa harus kesemua titik access point yang tersebar, tetapi kita cukup mendapatkan pancaran sinyal dari aplikasi tersebut untuk dapat melakukan pengecekan disatu titik saja.

Aplikasi ini dirancang untuk memonitoring bandwidth pada access point dan menjadi salah satu referensi PT.Telekomunikasi dalam melakukan pemantauan dilapangan. Setelah melakukan prosess monitoring menggunakan aplikasi ini maka data yang didapat akan tersimpan kedalam tabel monitoring. Informasi yang terdapat didalam tabel monitoring ini sendiri tersimpan di database phpMyAdmin yang berisikan tabel dan data yang didapat sesuai perintah yang telah diberikan. Data yang didapat akan diexport kebentuk excel hal ini berfungsi agar data hasil monitoring yang didapat bisa dikirim ketim PT.Telkom yang ada dikantor untuk mengelolah data yang didapat jika terjadi gangguan. Tetapi jika tidak terjadi gangguan data yang dikirim hanya 1 kali dalam sehari. Kemudian data yang telah diubah kebentuk excel akan dikirim melalui email.

\subsection{Pembahasan}

Membahas hasil dari aplikasi yang telah dibuat, aplikasi ini merupakan sebuah aplikasi berbasis web yang sudah berhasil dionline kan. Untuk memaksimalkan proses monitoring maka aplikasi ini dibuka melalui Laptop. Pada tahap ini akan menampilkan setiap tampilan halaman beserta penjelasan tentang pengoperasian aplikasi yang telah . Aplikasi ini bernama Aplikasi LINDRA.

1. Halaman Login Admin

Pada halaman ini admin dapat memasukan Username dan Password yang telah didaftarkan sebelumnya, agar dapat masuk kedalam aplikasi Lindra. Orang yang dapat login ke aplikasi ini adalah admin yang telah memilik user yang udah didaftarkan agar data yang didapat tidak disalah gunakan oleh orang lain. Tampilan awal halaman login sebagai berikut: 
Jurnal Riset Sistem Informasi Dan Teknik Informatika (JURASIK)

Volume (4) Juli 2019, pp 106-116

ISSN: 2527-5771/EISSN: 2549-7839

http://tunasbangsa.ac.id/ejurnal/index.php/jurasik

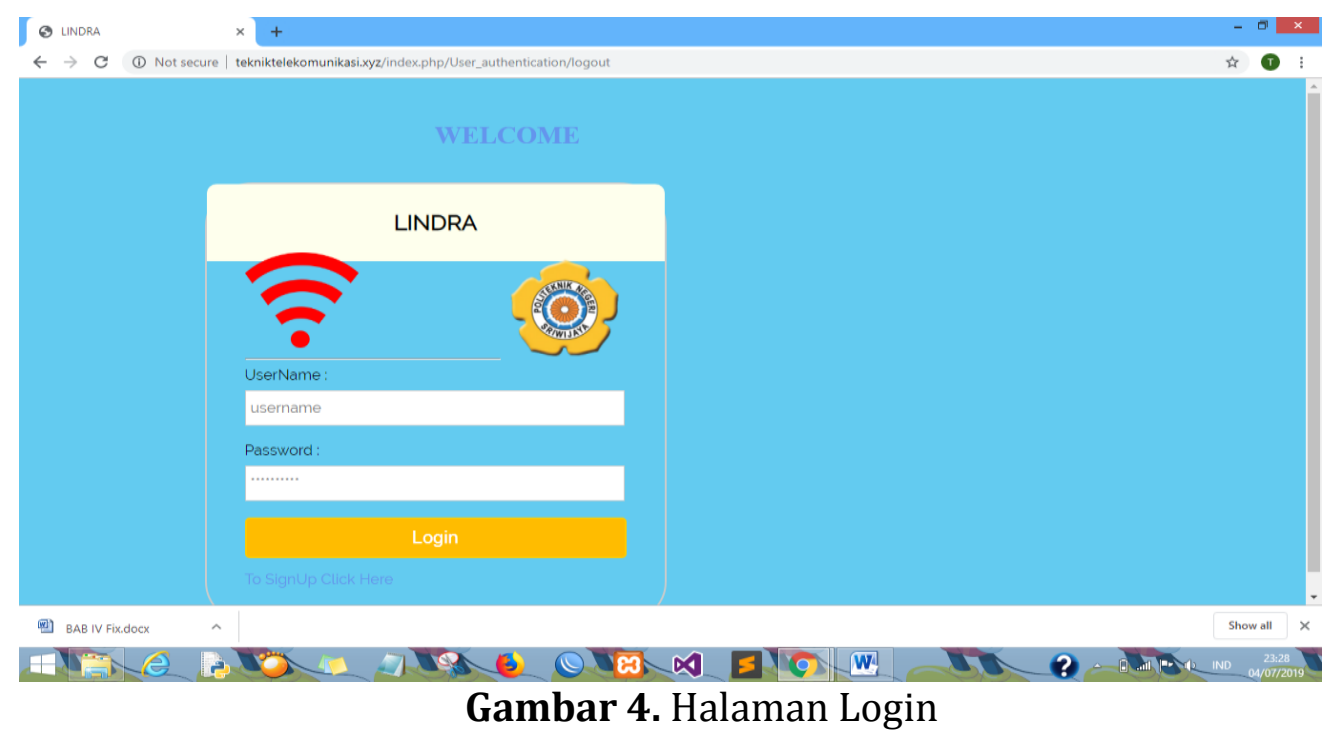

2. Halaman Awal Aplikasi Lindra

Pada tampilan ini menunjukan halaman awal yang ada pada Aplikasi Lindra. Pada halaman awal aplikasi Lindra mengucapkan selamat data untuk para pengguna aplikasi ini. Halaman awal aplikasi Lindra seperti gambar dibawah ini.

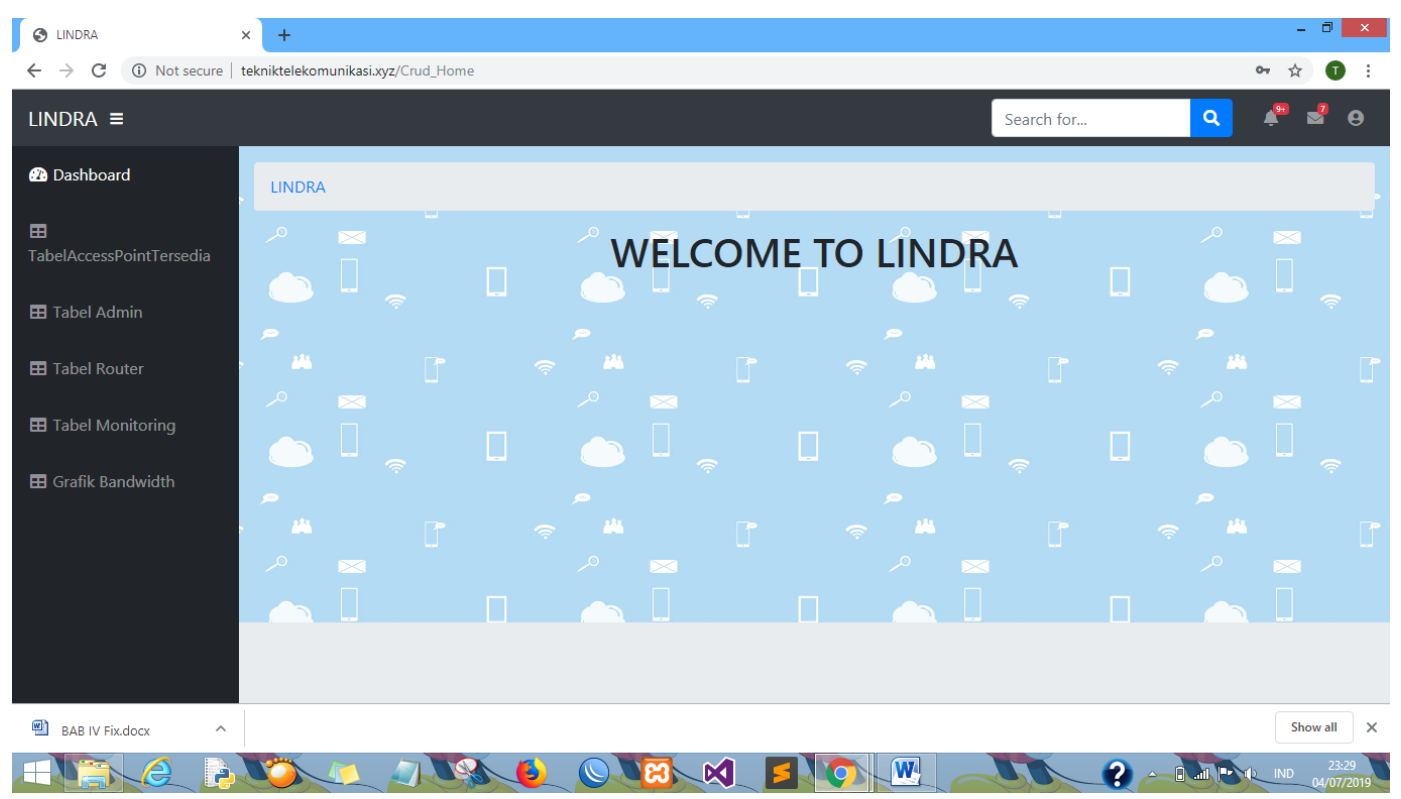

Gambar 5. Halaman Awal Aplikasi Lindra

3. Halaman Tabel Access Point Tersedia

Pada halaman ini akan menampilkN beberapa access point yang aktif disatu lokasi yang sudah tersebar beberapa titik access point. Pada tampilan ini kita dapat melihat access point yang mendapatkan pancaran sinyal yang dikeluarkannya. 
Jurnal Riset Sistem Informasi Dan Teknik Informatika (JURASIK)

Volume (4) Juli 2019, pp 106-116

ISSN: 2527-5771/EISSN: 2549-7839

http://tunasbangsa.ac.id/ejurnal/index.php/jurasik

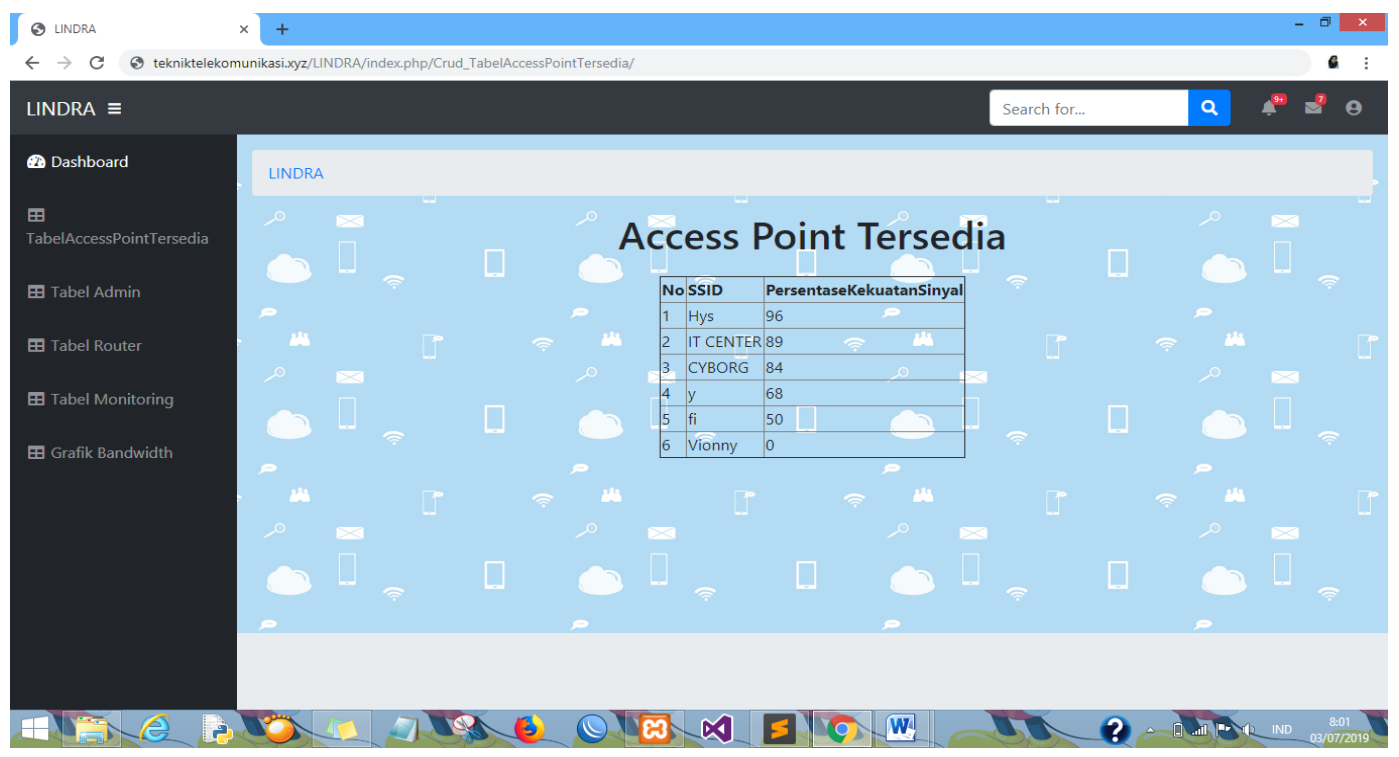

Gambar 6. Halaman Tabel Access Point Tersedia

4. Halaman Tabel Admin

Pada halaman ini menunjukkan tabel yang berfungsi untuk menginput data user untuk proses login Aplikasi Lindra, agar admin yang bertugas melakukan pemantauan dilapangan dapat masuk kedalam Aplikasi ini seduai dengan user yang telah didaftarkan.

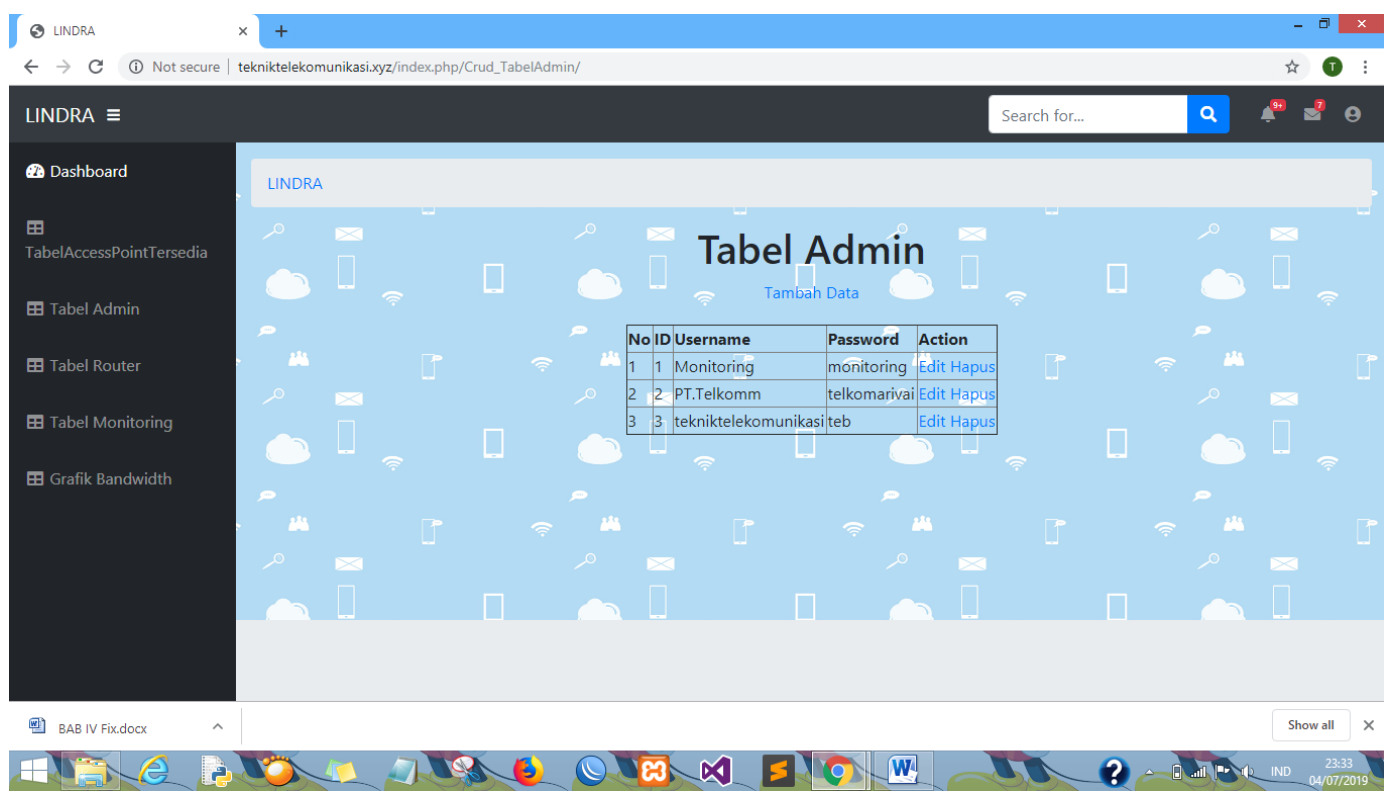

Gambar 7. Halaman Tabel Admin

5. Halaman Tabel Router

Pada halaman ini kita harus memasukan atau menginput data berupa Username dan Password dari setiap WiFi.Id yang akan dilakukan pengecekan. Setelah data berhasil 
di input maka kita dapat langsung menghubungkan salah satu sinyal WiFi tersebut agar kita dapat melakukan proses pengecekan lebih lanjut.

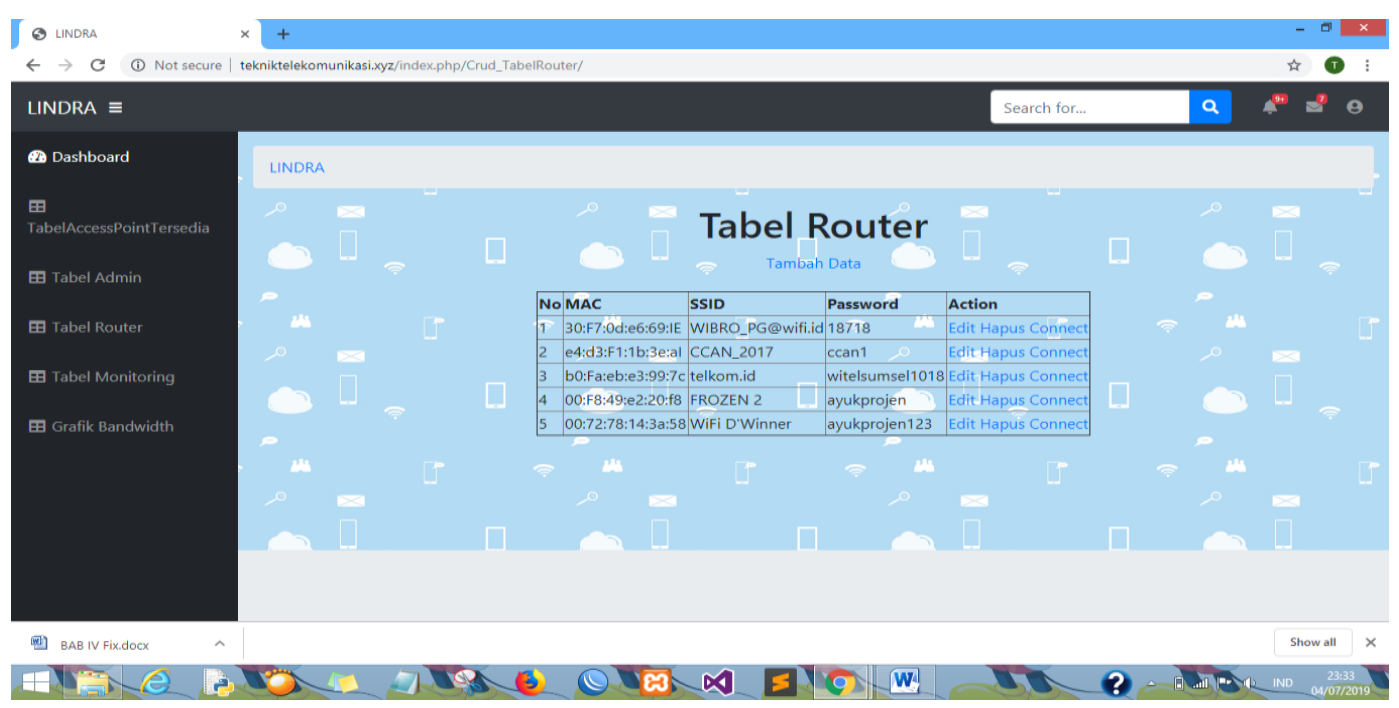

Gambar 8. Halaman Tabel Router

6. Halaman Bandwidth

Pada halaman router diatas, setelah diconnect ke access point yang akan dimonitorig maka diakan menuju kehalaman bandwidth berikut ini. Pada halaman ini menjukan tampilan bandwidth yang berisikan kecepatan nilai Upload dan Download setiap WiFi.Id yang telah dihubungkan sebelumnya. Pada tampilan bandwidth juga akan menunjukan nilai ping dan Jitter setiap sinyal WiFI.Id yang terhubung. Pengecekan ini dilakukan untuk mengetahui kualitas setiap WiFi.Id apakan dalam keadaan stabil atau tidak. Jika saat proses pengecekan terjadi permasalahn pada pancara sinyal access ponit maka tim admin dilapangan akan melaporkan data yang didapat kepada tim yang ada di kantor untuk melakukan proses perbaikan. Berikut gambar dari tampilan Bandwidth.

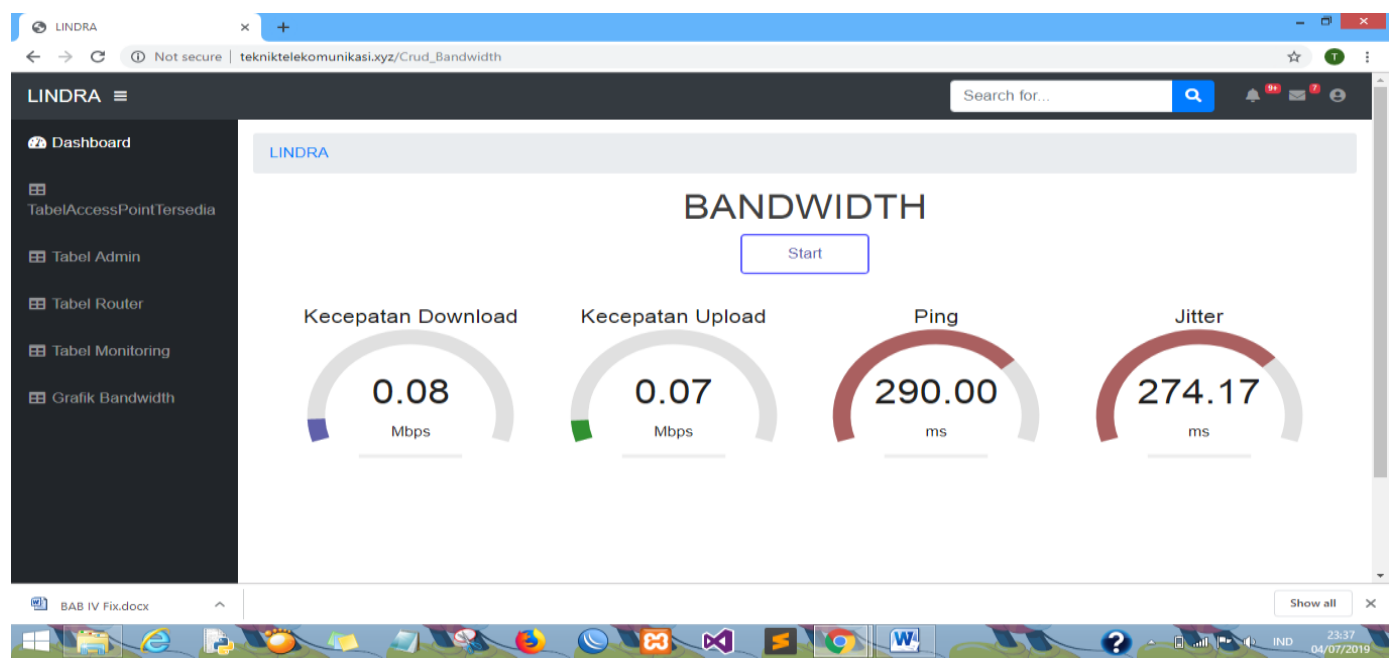

Rancang Aplikasi Monitoring Performance WiFi.Id PT.Telekomunikasi (Ayu Maulisa Lindra) | 113 
Gambar 9. Halaman Monitoring Bandwidth

\section{Halaman Tabel Monitoring}

Pada Tampilan ini merupakan halaman untuk penyimpanan data hasil dari pengecekan data, pada halaman ini kita akan mengetahui waktu saat melakukan poengecekan bandwidth dari access point WiFi.Id yang tersebar dibeberapa titik dilapangan. Setelah data didapatkan maka data akan dikirmkan ke pihak admin yang ada dikantor Telkom. Jika terjadi gangguan yang terjadi dilapangan maka tim lapangan akan memperbaikinya tetapi jika ada bagian dari jaringan maka tim dikantor akan membantu memperbaiki. Hal ini bertujuan memberikan layanan terbaik untuk para penggunan layanan WiFi.Id

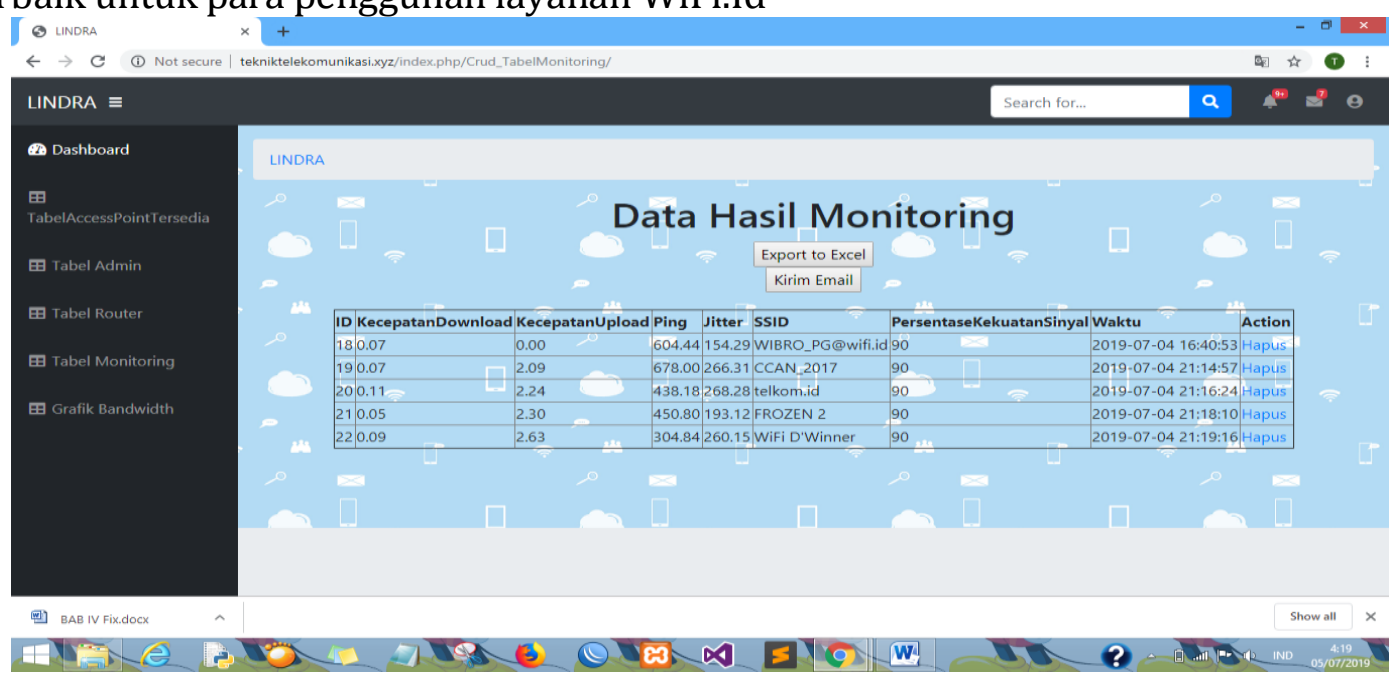

Gambar 10. Halaman Data Hasil Monitoring

8. Halaman Grafik Bandwidth

Pada halaman ini akan menampilkan grafik dari Kecepatan Upload, Kecepatan Upload, Ping, Jitter dari data yang telah didapat dan akan menginformasikan grafik pada waktu yang telah dibuat.

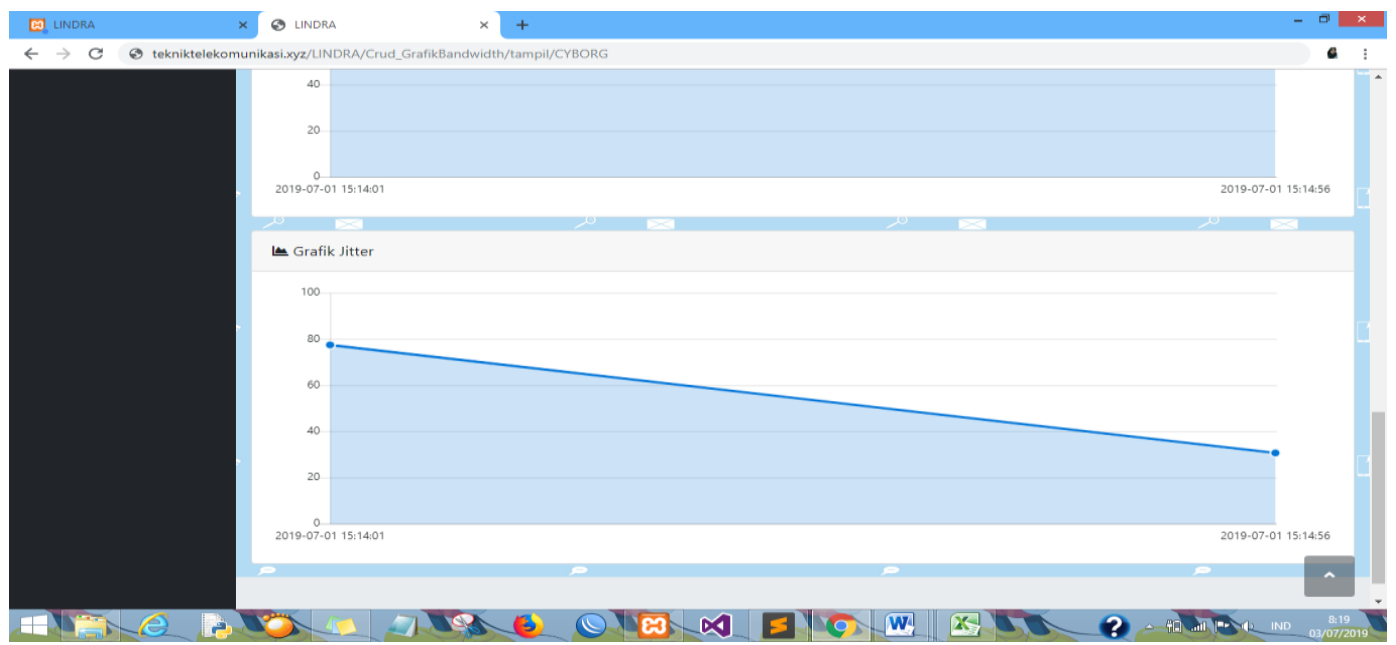

Gambar 11. Halaman Grafik Bandwidth 


\section{Halaman Excel}

Pada halaman ini akan membuka data excel, data yang ada pada excel ini merupakan data yang ada ditabel monitoring kemudia diexport kedalam bentuk excel. Data ini merupakan data hasil monitoring yang telah dilakukan.

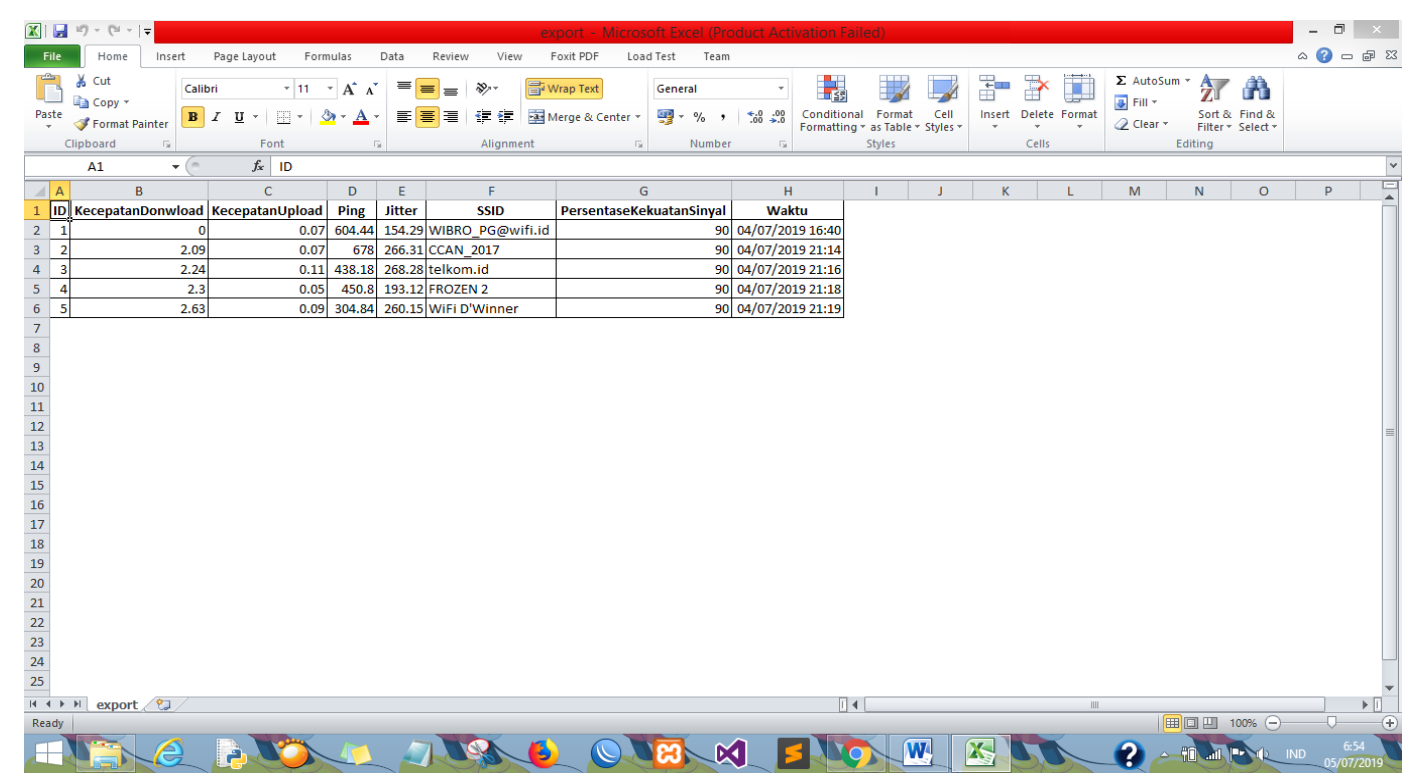

Gambar 12. Halaman Export to Excel

10. Halaman Email

Pada halaman ini akan menampilkan data tabel yang di export kebentuk excel dikirimkan kepada email admin yang ada. Untuk melakukan proses pendataan disaat sudah melakukan proses monitoring atau jika terjadi gangguan dilapangan saaat proses monitoring sudah dilakukan. 


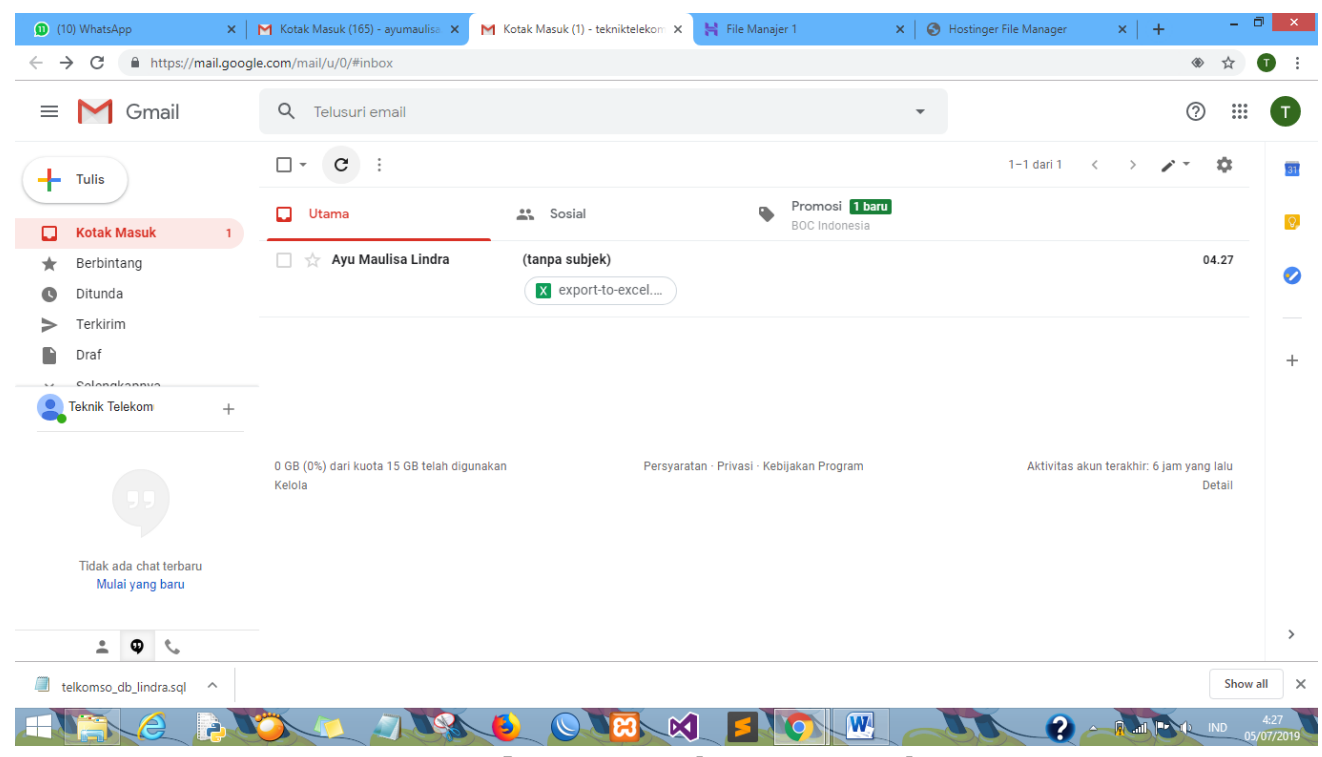

Gambar 13. Halaman Email

\section{SIMPULAN}

Pada penelitian kali ini dibuat sebuah aplikasi yang berjudul Aplikasi LINDRA. Aplikasi ini dibuat dengan tujuan untuk membantu melakukan proses pemantauan WiFI.Id yang tersebar dibeberapa titik dilapangan. Aplikasi Lindra ini memiliki keutamaan yaitu dapat melakukan pengecekn WiFI.Id dilapangan dari beberpa access point yang tersebar tanpa harus kesumua titik access point tersebut, dengan syarat kita masih mendapatkan pancaran sinyak access pointitu sendiri. Aplikasi ini dapat melihat apakah sinyal internet yang dikeluarkan oleh setiap access point tersebut dalam keadaan stabil dan baik jika tidak maka data yang didapatkan akan dilaporakan kepada tim yang ada dikantor untuk melakukan proses perbaikan. Hal ini dilakukan agar para pengguna layanan WIFi.Id selalu menikmati layanan yang digunakan dengan baik dan puas.

\section{DAFTAR PUSTAKA}

[1] Rahmatia Karim, Stevi S. Sumendap, F.V.I.A Koagouw "PENTINGNYA PENGGUNAAN JARINGAN WI-FI" Volume V. No.2. Tahun 2016.

[2] Muhammad Yogi, Yuliana, Joko Triyono "Analisi Kepuasan Pengguna Atas Kualitas Layanan jaringan WiFI Di IST AKPRIND Berdasarkan Kinerja Jaringan Wireless" Vol. 5No. Juni 2018 ISSN:2338-6304.

[3] Elpiani Apipah, Marzuki "Analisa Dan Perancangan Jaringan Komputer Menggunakan Teknologi Nirkabel Berbasis WiFI" Vol. II No.1 1 Februari 2016

[4] Westi Yulia, Yasdinul Huda "Analisis Kualitas Layanan Jaringan Internet WiFi.Id Menggunakan Parameter QoS" Vol. 7, No. 1, Maret 2019 E - ISSN: 2302-3295

[5] Ginanjar Wiro Sasmito "Penerapan Metode Waterfall Pada Desain Sistem Informasi Geografis Industri Kabupaten Tegal " Jurnal Pengembangan IT (JPIT), Vol.2, No 1, 1 Januari 2017 ISSN:2477-5126 e-ISSN:2548-9356 